\title{
New formula for lattice dimension of an oxide spinel with cubic structure
}

\author{
G M BHONGALE, D K KULKARNI and V B SAPRE* \\ Department of Physics, Institute of Science, Nagpur 440001, India \\ -Department ol Physics, Nagpur University, Nagpur 440001, India \\ MS received 18 April 1991; revised 12 December 1991
}

Alstract. An empirical relation between lattice parameter and cationic radii for cubic spinels has been established by considering the packing of anions in non-ideal situation and ionic displacement parameter $(\delta=z-3 / 8)$. This relation gives the value of $a$, the lattice parameter, which is much closer to the observed value.

Keywords. Lattice dimension; oxide spinel; cubic structure; cationic radii.

\section{Introduction}

Oxide spinels, whose properties depend on the valence and site distribution of the cations, have wide range of applications. The cationic distribution can be estimated from site preference energies, size of the ions, type of bonds, diffraction line intensities, etc. Considering divalent ionic radius of oxygen to be $1-40 \AA$, Mikheev (1955) gave an empirical relation to determine the lattice parameter $a$ as

$$
a=5 \cdot 778+0.95 r_{a}+2 \cdot 79 r_{b},
$$

where $r_{a}$ and $r_{b}$ are the tetrahedral and octahedral cationic radii respectively, Equation (1) is based on Goldschrnidt (1935) ionic radii. This relation, though helps in understanding the site distribution (Somenkoy 1964), does not yield values that match very closely with the experimental results. Moreover, it does not take care of the coordination polyhedra and the spin states of the cations.

Azaroff (1977) discussed the dependence of unit cell dimensions of crystalline solids upon the constituent ions in specific arrangement and packing. Many have attempted to determine the absolute values of ionic radii which depend only on the valency of ions (Goldschmidt 1935; Pauling 1939; Ahrens 1952; Sanderson 1967). Shannon and Prewitt $(1969,1970)$, in addition to the valency of ions, considered the influence of the coordination polyhedra and spin states. We therefore thought it worthwhile to establish a relation between ionic radii and lattice parameter of a cubic spinel.

In cubic spinel, $A$ site ion has a coordination number 4 . The ionic displacement parameter $\delta$, is correlated with $r_{a}$ and $r_{a}$, the ionic radii of cations at $A$ site and the oxygen anions respectively. The lattice parameter $a$ is then calculated in terms of $\delta$, $r_{a}, r_{b}$ and $r_{b}$. In the spinel structure $\mathrm{AB}_{2} \mathrm{O}_{4}$, there are two or more types of metal atoms linked to the oxygen atom either tetrahedrally or octahedrally. The former is usually referred to as $A$-site and the latter as $B$-site. The cation at $A$-site is surrounded by 4 oxygen jons while each oxygen ion is surrounded by 4 cations, of which one is from $A$-site and the remaining three from $B$-site. Hence, even though the oxygen ion is tetrahedrally coordinated, the first coordination sphere of oxygen is influenced by distances of $\mathrm{B}-\mathrm{O}$ type of bond. Therefore it is appropriate to take $r_{\mathrm{a}}=1.40 \AA$ which is oxygen ion radius for six-coordination as given by Shannon and Prewitt (1969). 
On substituting for $\delta$ in terms of $r_{a}$ and $r_{b}$, we get the relation between $a, r_{a}$ and $r_{b}$ which is independent of $\delta$ (derivation of the relation is given in appendix). The relation obtained is:

$$
\begin{aligned}
a= & \left\{\left(r_{a} / \sqrt{ } 3+r_{b}+2.0951 r_{b}\right)+\left[\left(r_{a} / \sqrt{ } 3+r_{b}+2.0951 r_{o}\right)^{2}\right.\right. \\
& \left.\left.-1.866\left(1.3333 r_{a}^{2}+0.0675 r_{a}^{2}-0.6 r_{a} r_{o}\right)\right]^{1 / 2}\right\} / 0.933,
\end{aligned}
$$

where $r_{a}$ and $r_{b}$ are the tetrahedral and octahedral cationic radii respectively. We have used the above relation to calculate the lattice parameter $a$ in the well-known compounds with definite valencies and site distributions.

\section{Results and discussion}

Table 1 gives the calculated values of lattice parameter $a$ for some oxide spinels using our formula and employing the values of ionic radii given by Shannon and Prewitt $(1969,1970)$. For comparison, in table 1 are ajso given the values of $a$ calculated by

\begin{tabular}{|c|c|c|c|c|}
\hline Spinels & $\begin{array}{l}\text { Iont at } \\
\text { A-site }\end{array}$ & $\begin{array}{c}\text { Observed } \\
a(\bar{A})\end{array}$ & $\begin{array}{c}\text { Calculated by } \\
\text { Mikheov's formula } \\
a(A)\end{array}$ & $\begin{array}{c}\text { Calculated by } \\
\text { Authors' formanla } \\
a(\AA)\end{array}$ \\
\hline $\operatorname{CdAl}_{2} O_{4}$ & $\mathrm{Cd}^{2-}$ & $8 \cdot 137$ & 8017 & 8.333 \\
\hline $\mathrm{CdCr}_{2} \mathrm{O}_{4}$ & $\mathrm{Cd}^{2+}$ & 8.467 & $8 \cdot 240$ & 8.506 \\
\hline $\mathrm{CdFe}_{2} \mathrm{O}_{4}$ & $\mathrm{Cd}^{2+}$ & 8.690 & $8 \cdot 324$ & 8.571 \\
\hline $\mathrm{CdGa}_{2} \mathrm{O}_{4}$ & $\mathrm{Cd}^{2+}$ & 8.390 & 8268 & $\overline{8.528}$ \\
\hline $\mathrm{CdMn}_{2} \mathrm{O}_{4}$ & $\mathrm{Cd}^{2+}$ & 8220 & 8156 & 8.441 \\
\hline $\mathrm{CdV}_{2} \mathrm{O}_{4}$ & $\mathrm{Cd}^{2+}$ & 8695 & 8.323 & 8.571 \\
\hline $\mathrm{FeCoCtO}_{4}$ & $\mathrm{Fe}^{3+}$ & $8 \cdot 340$ & $8 \cdot 127$ & B.330 \\
\hline $\mathrm{FaCr}_{2} \mathrm{O}_{4}$ & $\mathrm{Fe}^{2+}$ & $8 \cdot 340$ & 8.078 & $\underline{8-341}$ \\
\hline $\mathrm{FeCuMnO}_{4}$ & $\mathrm{Fe}^{3+}$ & $8 \cdot 340$ & $8 \cdot 169$ & $8: 363$ \\
\hline $\mathrm{FeMnNiO}_{4}$ & $\mathrm{Fe}^{3-1}$ & 8.360 & $8: 112$ & $8: 319$ \\
\hline $\mathrm{FeV}_{2} \mathrm{O}_{4}$ & $\mathrm{Fe}^{2+}$ & 8.550 & 8. 162 & 8.405 \\
\hline $\mathrm{GeFe}_{2} \mathrm{O}_{4}$ & $\mathrm{Ge}^{4}$ & 8.420 & 8.334 & $\underline{8.452}$ \\
\hline $\mathrm{MgAl}_{2} \mathrm{O}_{4}$ & $\mathrm{Mg}^{2+}$ & 8.086 & 7.808 & $\underline{8+117}$ \\
\hline $\mathrm{MgCo}_{2} \mathrm{O}_{4}$ & $\mathrm{Mg}^{2+}$ & 8.107 & 7.779 & 8095 \\
\hline $\mathrm{MgCr}_{2} \mathrm{O}_{4}$ & $\mathrm{Mg}^{2+}$ & $8 \cdot 322$ & 8.031 & 8.289 \\
\hline $\mathrm{MgFe}_{2} \mathrm{O}_{4}$ & $\mathrm{Mg}^{2+}$ & 8.352 & $8 \cdot 115$ & 8353 \\
\hline $\mathrm{MgGa}_{2} \mathrm{O}_{4}$ & $\mathrm{Mg}^{2+}$ & 8.260 & 8.059 & 8310 \\
\hline $\mathrm{MgMr}_{2} \mathrm{O}_{4}$ & $\mathrm{Mg}^{2+}$ & 8.080 & 7.947 & $\underline{8.224}$ \\
\hline $\mathrm{MgV}_{2} \mathrm{O}_{4}$ & $\mathrm{Mg}^{2+}$ & 8416 & $8-114$ & 8.353 \\
\hline $\mathrm{MnCoFeO}_{4}$ & $\mathrm{Mn}^{2+}$ & $8 \cdot 410$ & 8033 & 8.413 \\
\hline $\mathrm{MnCrNiO}_{4}$ & $\mathrm{Mn}^{3+}$ & 8390 & 8442 & $\overline{8.375}$ \\
\hline $\mathrm{Mn}_{2} \mathrm{NiO}_{4}$ & $\mathrm{Mn}^{3+}$ & 8420 & 8.198 & 8.461 \\
\hline $\mathrm{MnNi}_{2} \mathrm{O}_{4}$ & $\mathrm{Mn}^{4+}$ & $8 \cdot 380$ & 8.216 & 8.418 \\
\hline $\mathrm{ZnAl}_{2} \mathrm{O}_{4}$ & $Z_{n^{2+}}$ & 8086 & 7.827 & 8.138 \\
\hline $\mathrm{ZnCo}_{2} \mathrm{O}_{4}$ & $\mathbf{Z n}^{2+}$ & 8.047 & 7.798 & $8-116$ \\
\hline $\mathrm{ZnCr}_{3} \mathrm{O}_{4}$ & $Z n^{2+}$ & $8: 312$ & 8.050 & 8.310 \\
\hline $\mathrm{ZnFe}_{2} \mathrm{O}_{4}$ & $\mathrm{Zn}^{2+}$ & 8.440 & $8 \cdot 134$ & 8.374 \\
\hline $\mathrm{ZnGa}_{2} \mathrm{O}_{4}$ & $\mathrm{Zn}_{\mathrm{n}^{2+}}$ & $8-370$ & 8.078 & 8.931 \\
\hline $\mathrm{ZnMn}_{3} \mathrm{O}_{4}$ & $\mathrm{Zn}^{2-}$ & 8.077 & 8970 & 8.245 \\
\hline $\mathrm{ZnV}_{2} \mathrm{O}_{4}$ & $\mathrm{Zn}^{2+}$ & 8.409 & $8 \cdot 133$ & 8.374 \\
\hline
\end{tabular}

Table 1. Observed and calculated lattice parameters.

Underlined values show closeness to the observed one. 
Table 2. Suitable spin states from observed lattice parameter.

\begin{tabular}{cc}
\hline $\mathrm{Mg}^{2+}\left[\mathrm{Mn}_{2}^{3+}\right] \mathrm{O}_{4}^{2-}$ & $\mathrm{Mg}^{2+}\left[\mathrm{Co}_{2}^{3+}\right] \mathrm{O}_{4}^{2-}$ \\
$\mathrm{L}$ & $\mathrm{L}$ \\
$\mathrm{Zn}^{3+}\left[\mathrm{Mn}_{2}^{3+}\right] \mathrm{O}_{4}^{2-}$ & $\mathrm{Zn}^{2+}\left[\mathrm{Co}_{2}^{3+}\right] \mathrm{O}_{4}^{2-}$ \\
$\mathrm{L}$ & $\mathrm{L}$ \\
$\mathrm{Cd}^{2+}\left[\mathrm{Mn}_{2}^{3+}\right] \mathrm{O}_{4}^{2-}$ & $\mathrm{Mg}^{2+}\left[\mathrm{Fe}_{2}^{3+}\right] \mathrm{O}_{4}^{2-}$ \\
$\mathrm{L}$ & $\mathrm{H}$ \\
$\mathrm{Mn}^{3+}\left[\mathrm{Mn}^{3+} \mathrm{Ni}^{2+}\right] \mathrm{O}_{4}^{2-}$ & $\mathrm{Zn}^{2+}\left[\mathrm{Fe}_{2}^{3-}\right] \mathrm{O}_{4}^{2-}$ \\
$\mathrm{H}$ & $\mathrm{H}$ \\
$\mathrm{Fe}^{3+}\left[\mathrm{Mn}^{3+} \mathrm{Ni}^{2-}\right] \mathrm{O}_{4}^{2-}$ & $\mathrm{Cd}^{2+}\left[\mathrm{Fe}_{2}^{3+}\right] \mathrm{O}_{4}^{2-}$ \\
$\mathrm{H}$ & $\mathrm{H}$ \\
$\mathrm{Fe}^{3+}\left[\mathrm{Mn}^{3+} \mathrm{Cu}^{2+}\right] \mathrm{O}_{4}^{2-}$ & $\mathrm{Ge}^{4+}\left[\mathrm{Fe}_{2}^{2+}\right] \mathrm{O}_{4}^{2-}$ \\
$\mathrm{H}$ & $\mathrm{H}$
\end{tabular}

$\mathrm{L}$, low spin state, $\mathrm{H}$, high spin state

Mikheev's formula by using values of ionic radii as given by Shannon and Prewitt $(1969,1970)$. A close observation of the table shows that the values of lattice parameter calculated by our formula are, in general, closer to the experimental results. The values of lattice parameter have also been calculated using the ionic radii given by Goldschmidt (1935), Pauling (1939), Ahrens (1952) and Sanderson (1967). However these values are not included in the table, since they differ widely from the values determined experimentally.

The values given in table 1 are accounted for low as well as high spin cationic stales. It is seen from table 2 that for cation $\mathrm{Mn}^{3+}$ existing at the $B$ site, just low or high spin ionic radii do not fit well in all the compounds. It is found that when $\mathrm{Mn}^{3+}$ ion is present along with a divalent neighbour at $B$ site, the high spin ionic radius is more suitable, while in the case of trivalent neighbour only the low spin ionic radius appears to suit well. The agreement in the case of high spin state is not surprising although uncommon for low spin states (table 2).

\section{Conclusions}

The refation given by us can be used to calculate the lattice parameter of oxide cubic spinels. It will also be a useful tool to decide the probable degree of inversion in the distribution of cations in the newly synthesized spinels.

\section{Appendix}

Derivation of relation for the lattice parameter $a$ :

Tetrahedral and octahedral bond lengths $R_{A}$ and $R_{B}$ in the cubic spinel are given as

$$
R_{A}=a \sqrt{3}\left(\frac{1}{8}+\delta\right) \text { and } R_{B}=a\left(\frac{1}{16}-\frac{\delta}{2}+3 \delta^{2}\right)^{1 / 2}
$$

The above equations give

$$
a=\frac{R_{A}+R_{B}}{\sqrt{3}\left(\frac{1}{8}+\delta\right)+\left(\frac{1}{16}-\frac{\delta}{2}+3 \delta^{2}\right)^{1 / 2}}
$$


Let

$$
D=\sqrt{3}\left(\frac{1}{8}+\delta\right)+\left(\frac{1}{16}-\frac{\delta}{2}+3 \delta^{2}\right)^{1 / 2}
$$

The second term of $D$ can be simplified as follows

$$
\begin{aligned}
\left(\frac{1}{16}-\frac{\delta}{2}+3 \delta^{2}\right)^{1 / 2} & =1 / 4\left(1-8 \delta+48 \delta^{2}\right)^{1 / 2} \\
& =1 / 4[1-8 \delta(1-6 \delta)]^{1 / 2}
\end{aligned}
$$

Using binomial expansion and neglecting higher powers of $\delta$ we get

$$
\left(\frac{1}{16}-\frac{\delta}{2}+3 \delta^{2}\right)^{1 / 2}=(1 / 4)-\delta+4 \delta^{2}
$$

Putting (A3) in (A2) we get

$$
D=(\sqrt{3} / 8)+\sqrt{3} \delta+(1 / 4)-\delta+4 \delta^{2}
$$

Consider that the anions are occupying four altcrnate corners of the cube of side $a$ and that the cation is at the centre. If $r_{a}$ is the radius of the sphere representing tetrahedral void (cation) and $r_{x}$ the radius of the (anion) sphere in the closest packing, we then have

$$
r_{x}=(\sqrt{2} / 2) a \text { and } r_{a}+r_{x}=(\sqrt{3} / 2) a
$$

Therefore $r_{a} / r_{x}=(\sqrt{3 / 2})-1=0225$. Thus for ideal ionic packing the allowed ionic radius for any ion of radius $r_{u}$ is given as $0.225 r_{x}$. In non-ideal situation, the expression would be $a \sqrt{3} \delta=r_{s}-0.225 r_{x}$, where $\delta=(u-3 / 8)$ is ionic displacement parameter. In an ideal packing $u=3 / 8$. In non-ideal packing $u>3 / 8$ and thc anion will move along the body diagonal of the cube. In that case

$$
\delta=\left(\frac{r_{0}-0.225 r_{x}}{\sqrt{3} a}\right)
$$

For oxygen ion $r_{x}=r_{o}$, hence

$$
\delta=\left(\frac{r_{a}-0.225 r_{o}}{\sqrt{3} a}\right) .
$$

Substituting the value of $\delta$ in expression (A4), we get

$$
D=\frac{\sqrt{3}}{8}+\sqrt{3}\left(\frac{r_{a}-0.225 r_{o}}{\sqrt{3} a}\right)+\frac{1}{4}-\left(\frac{r_{a}-0 \cdot 225 r_{o}}{\sqrt{3} a}\right)+4\left(\frac{r_{b}-0.225 r_{o}}{\sqrt{3} a}\right)^{2} .
$$

Now $R_{A}=r_{a}+r_{0}$ and $R_{B}=r_{b}+r_{0}$. Therefore $R_{A}+R_{B}=r_{a}+r_{b}+2 r_{b}$. From (A1)

Therefore

$$
a=\left(R_{A}+R_{B}\right) / D=\left(r_{a}+r_{b}+2 r_{0}\right) / D,
$$

$$
r_{a}+r_{b}+2 r_{a}=D_{a}
$$

Putting the value of $D$ from (A6) in (A7) and simplifying we get

$$
0.4665 a^{2}-\left(r_{a} / \sqrt{3}+r_{b}+2.0951 r_{a}\right) a+\left(1-3333 r_{a}^{2}+0.0675 r_{o}^{2}-0.6 r_{a} r_{a}\right)=0 .
$$


Taking positive root, we get

$$
\begin{aligned}
a= & \left\{\left(r_{a} / \sqrt{3}+r_{b}+2.0951 r_{a}\right)+\left[\left(r_{a} / \sqrt{3}+r_{b}+2 \cdot 0951 r_{a}\right)^{2}\right.\right. \\
& \left.\left.-1.866\left(1.3333 r_{a}^{2}+0.0675 r_{o}^{2}-0.6 r_{a}^{\prime} r_{c}\right)\right]^{1 / 2}\right\} / 0.933
\end{aligned}
$$

\section{References}

Ahrons 1952 Geochim. Cosmochim. Acta 2155

Azaroft L V 1977 in Introduction to solids, (Bombay: Tala-MoGraw-Hill) p. 67

Goldsclunidt V M 1935 in International Tobellen Zur Bestimmug Van Kristalstrakture

Mikheev V J 1955 Dokl. Akad. Nauk SSSR 101343

Pauling L 1939 Nature of chemical bond, (New York: Cornell University Press) 2nd Ed. p. 346

Sanderson R T 1967 Inorganic chemistry (New York: Reinhold Publishing Corporation) p. 136

Shannon R D and Prewitt C T 1969 Acta Crystallogr. B25 925

Shannon R D and Prewitl C T 1970 Acta Crystallogr. B26 1046

Somenkov V A 1964 Fiz metal metalioved 18853 